\title{
Advances in research on the deep South China Sea circulation
}

\author{
TIAN JiWei ${ }^{1 *} \&$ QU TangDong ${ }^{2}$ \\ ${ }^{1}$ Physical Oceanography Laboratory, Ocean University of China, Qingdao 266003, China; \\ ${ }^{2}$ International Pacific Research Center, School of Ocean and Earth Science and Technology (SOEST), University of Hawaii, \\ Honolulu 96822, USA
}

Received November 6, 2011; accepted April 18, 2012; published online June 17, 2012

\begin{abstract}
Deep sea circulation is important for world climate and has been a substantial research area in ocean science, leading to various breakthroughs and discoveries. With the rapid advance in research on ocean science, these matters have received increasing attention from the oceanography community. In this article, we attempt to convey the progress made in recent years. We first provide an overview of existing observations, theories, and simulations of deep South China Sea circulation. Finally, we discuss remaining issues.
\end{abstract}

deep South China Sea circulation, Bashi Channel, mass transport, energy transport, topography, turbulence

Citation: $\quad$ Tian J W, Qu T D. Advances in research on the deep South China Sea circulation. Chin Sci Bull, 2012, 57: 3115-3120, doi: 10.1007/s11434-012-5269-x

The South China Sea (SCS) is the largest marginal sea of the northwest Pacific. Its unique environment plays a significant role in the deep circulation, sediment transport and abyssal carbon cycle, making it a natural platform for multidisciplinary experiments of ocean dynamics, sediment dynamics and biogeochemistry. As a part of the global deep-sea circulation, the deep SCS circulation results from interaction among multi-scale dynamic processes and complex topography, which in turn determine the regional sediment transport and abyssal carbon cycle. The circulation is sustained by the deep overflow and internal tide energy flux of the Bashi Channel (BC). Thus, understanding the spacetime structure and variability of the deep SCS circulation depends on knowledge of several key issues. These include mass and energy transport through the $\mathrm{BC}$, constraints of topography on flow paths, and mechanisms of abyssal turbulence.

The BC is the only deep passage connecting the Pacific and SCS. The deep Pacific water passing through the BC is known as "the deep overflow through Luzon Strait". This penetrates the SCS through the Luzon Trough (LT) and Manila Trench, which is called the Luzon Strait/Manila

*Corresponding author (email: tianjw@ouc.edu.cn)
Trench deep circulation. The deep SCS circulation refers to the circulation system below about $2000 \mathrm{~m}$ depth in the SCS basin. Its exact upper boundary is defined by the minimum potential density of the deep Pacific water passing through the BC. The Luzon Strait/Manila Trench deep circulation is a substantial band connecting the Pacific and deep SCS circulation. As such, it is important in sustaining the heat and mass balance of the SCS, supporting the SCS throughflow [1], and influencing the SCS sediment transport and carbon cycle [2-11].

The $\mathrm{BC}$ is also significant in energy exchange between the Pacific and SCS. Enormous internal tide energy $(\sim 10$ $\mathrm{GW}$ ) is generated at the BC and is propagated into the SCS. This feeds the deep SCS mixing process, making it two orders larger than that in the deep Pacific. Enhanced diapycnal mixing triggers deep vertical convection and drives the cyclonic circulation in the deep SCS, dominating the residence time of deepwater there [7].

The Luzon Strait/Manila Trench deep circulation and deep SCS circulation represent a deep circulation system constituted by the western boundary current in the Philippine Basin. Its structure and variation are the joint effect of interaction among the three circulations, the constraint of complex topography, and regulation of enhanced mixing in 
the deep ocean. Hence, study of this system will help address the palaeo-oceanographical reconstruction and life cycle of the marginal sea, and advance research on climate change and the SCS deep carbon cycle.

\section{Observation of western boundary of the Philippine Basin}

The deep circulation in the Philippine Basin (upstream of the $\mathrm{BC}$ ) and its variation and dominant mechanisms are important for volume transport of the deep BC and even deep SCS circulation. The World Ocean Circulation Experiment (WOCE) has made great progress in studying global ocean circulation. It has strengthened our knowledge of this circulation, especially in the deep Pacific. The deep western boundary current of the southern Pacific passes through Kermadec Ridge and enters the central Pacific Basin through the Samoan Passage, where deep volume transport is $6-8 \mathrm{~Sv}$ [12-15]. Then, after going a little further north, it splits into two branches. The eastern branch has deeper and colder components, and the western branch has water from shallower levels. The eastern branch to the east of the Tuvalu and Gilbert Islands crosses the equator and goes further north, east of the Marshall Islands. Its main flow moves into the northwest Pacific Basin through the Wake Island Passage, with volume transport $\sim 4 \mathrm{~Sv}$ [16]. It proceeds further along the Japan [17], Kuril [18] and Aleutian Trenches [19], ultimately entering the northeast Pacific basin. It is known as the primary component of the anticyclonic circulation in the Pacific. The western branch penetrates the Melanesia Basin and goes northwest, where it crosses the equator and enters the eastern Mariana Basin, carrying $4 \mathrm{~Sv}$ of deep water. It splits again south of the Mariana Basin. One branch goes to the northwest Pacific
Basin, and the other flows through the western Mariana Basin and reaches the Philippine Basin (Figure 1).

To study the western boundary current in the Philippine Basin, a mooring system was deployed off the eastern coast of Bataan Island (Figure 2(a)) in August 2010, and was recovered in April 2011. It had a recording current meter (RCM) moored at a depth of $2950 \mathrm{~m}$, about $120 \mathrm{~m}$ above the bottom. Results show that constrained by topography, meridional velocity prevails east of Bataan Island, with 16-d low-passed velocities up to $8 \mathrm{~cm} \mathrm{~s}^{-1}$ (Figure 2(b)). Seasonal variation is also revealed from the meridional velocity, implying that the western boundary current there goes southward in summer and northward in winter. Hence, deep water entering the SCS through the BC could be anticipated to come from the deep western part of the Philippine Basin, north of the BC in summer and south in winter. This is different from the path conjectured from sediment transport. Further continuous observations of the deep current east of Taiwan and Bataan Island are needed, to ascertain the path and volume transport of deep water through the $\mathrm{BC}$ from the deep Pacific.

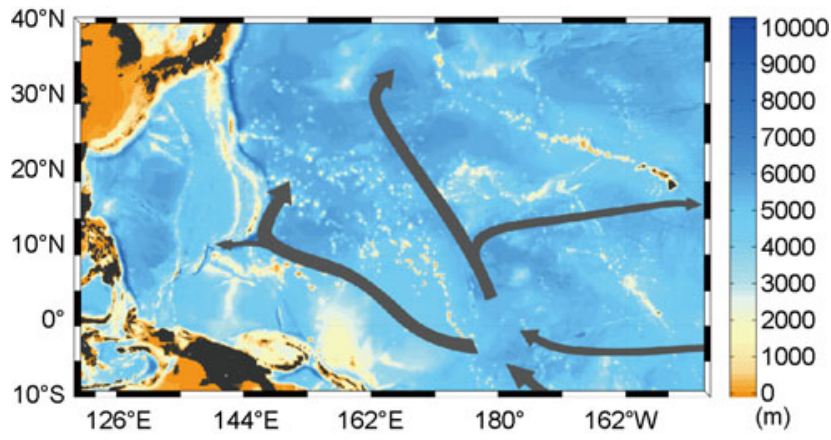

Figure 1 Approximate flow paths of Lower Central Pacific Water (LCPW) in western Pacific. Modified from [12,20].
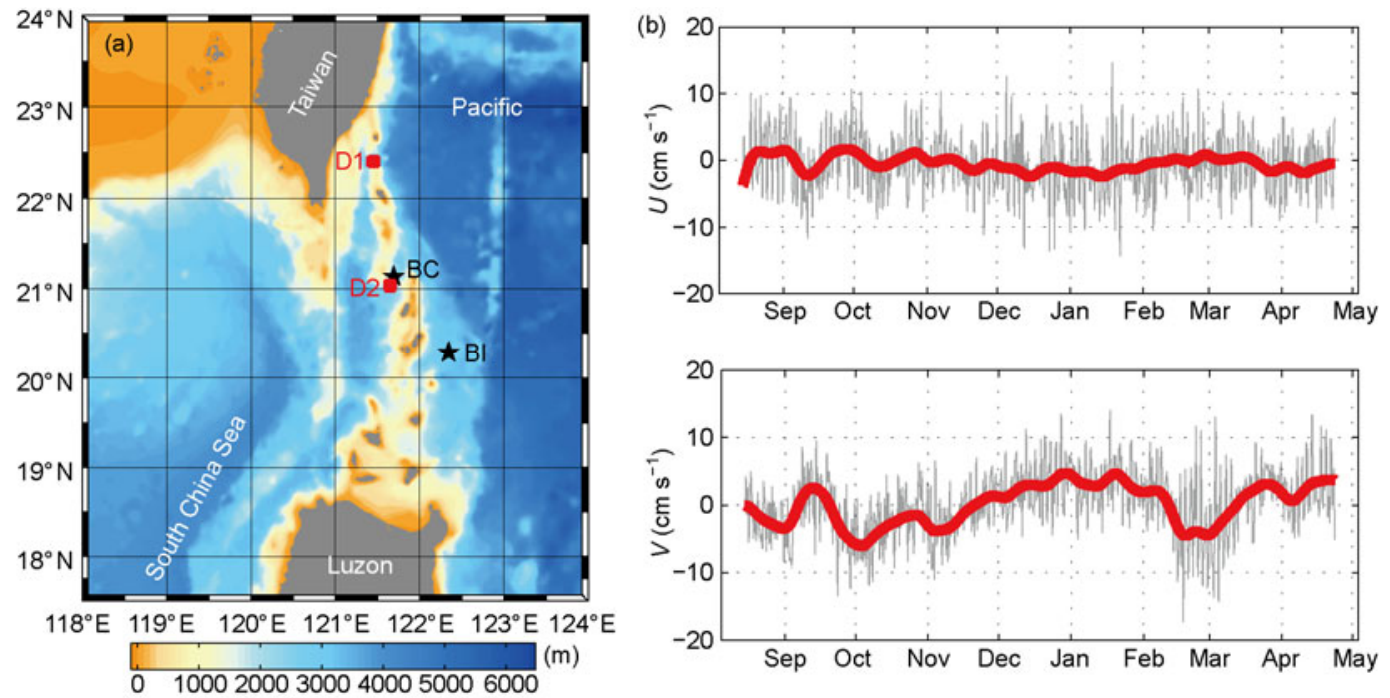

Figure 2 (a) Locations of mooring systems at BC and east of the Bataan Island (BI), as well as those of Chang et al. at Taltung Canyon (D1) and BC (D2); (b) result of RCM at BI (gray line indicates observed velocity and red line 16-d low-passed velocity). 


\section{Deep circulations and their volume transport in the BC, Luzon Strait and Manila Trench}

In the 1970s, through comparison of thermohaline characteristics of the deep SCS and Philippine Basin, deep water in the SCS was speculated to originate from the deep northwest Pacific and pass through the BC [21-23]. There has been increased attention to the overflow of the deep $\mathrm{BC}$, and great progress made in understanding of its structure and volume transport [6,8,9,24-32]. Based on the World Ocean Database, Qu et al. [9] showed that between the Pacific and SCS there was a persistent baroclinic pressure gradient below $1500 \mathrm{~m}$, driving inflow through the BC. Qu et al. [9] estimated volume transport of the overflow at 1-2.5 Sv. With the latest current and hydrologic observations, Tian et al. [6] and Yang et al. [8] quantified the structure and volume transport of each layer in the BC. Water-mass analysis revealed that after entering the SCS, cold and salty deep Pacific water generates a cyclonic deep circulation.

Chang et al. [33] deployed two mooring systems at the BC and Taltung Canyon in April and July 2007, respectively, and recovered them in January 2008. They examined water exchange in the deep Luzon Strait (Figure 2(a)), indicating that the $\mathrm{BC}$ was the main passage for the deep Pacific water passing through the Luzon Strait, with volume transport of 1.06 $\pm 0.44 \mathrm{~Sv}$ and intra-seasonal variation (Figure 3).

Tian et al. have made continuous observations of the deep overflow through the BC (Figure 2(a)) since October 2009 , to study its structure and variation. Results at the BC revealed the deep Pacific water penetrated the SCS
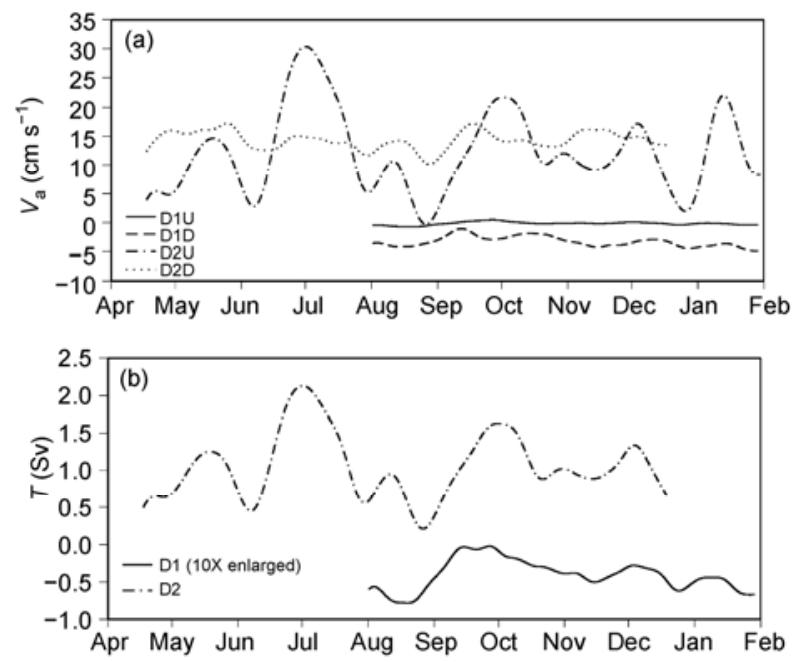

Figure 3 Along-channel (Va) and Volume Transport (T) of the D2 and D1 (modified from [33]). (a) 15-d low-passed along-channel velocity after counterclockwise coordinate rotation of $100^{\circ}$ and $135^{\circ}$ at D1 and D2, respectively (D1U and D1D represent results from RCMs at depths $2714 \mathrm{~m}$ and $2960 \mathrm{~m}$ at D1; D2U and D2D represent results from RCMs at depths $2262 \mathrm{~m}$ and $2695 \mathrm{~m}$ at D2); (b) corresponding along-channel volume transport at D2 (dot-dash line), and D1 with 10 times vertical exaggeration (solid line). through the BC with a background current up to $40 \mathrm{~cm} \mathrm{~s}^{-1}$ and average velocity of $23.1 \mathrm{~cm} \mathrm{~s}^{-1}$ (Figure 4), much larger than that in the deep open ocean $\left(\sim 1 \mathrm{~cm} \mathrm{~s}^{-1}\right)$.

\section{Observation system of deep SCS circulation}

Given a lack of direct observation of current, characteristics of the deep SCS circulation are poorly understood, except for some qualitative or partially quantitative conjecture.

Based on large amounts of current, temperature, salinity, and dissolved oxygen (DO) profiles in the Luzon Strait, Zhao et al. looked into the transport of deep water through the Luzon Strait (Figure 5, personal communication). Their analysis revealed that the deep Pacific water penetrated the SCS through the Luzon Strait, with corresponding volume transport of $1.5 \mathrm{~Sv}$. The BC served as the main gap for the penetration with volume transport of $1.2 \mathrm{~Sv}$. The deep water flowed out of the Luzon Strait through three gaps of the west wall, the Heng-Chun Ridge, the middle two gaps of which served as the main exits for deep water. Further study will be done by Zhao et al. to delineate the pathway of the deep Pacific water through the Luzon Strait into the SCS and the volume transport of each sill during the penetration.

Wang et al. [34] recently calculated the deep geostrophic current of the SCS based on the U.S Navy Generalized Digital Environment Model (GDEM) global climatological monthly mean temperature and salinity dataset (Figure 6). A basin-scale cyclonic circulation was evident over the deep SCS, consistent with the corollary of Qu et al. [9] according to water-mass analysis. There was also a strong and uniform abyssal flow southward, from the bottom to $2000 \mathrm{~m}$ depth, along $116^{\circ} \mathrm{E}$. Low salinity water was discovered in the interior region west of Luzon Island, and the potential density distribution was similar to that of salinity. This implies that the cyclonic circulation in the deep SCS was controlled by salinity variations in the deep basin. However, topography played a significant role in the distribution and variation of salinity in the deep SCS.

According to results of Simple Ocean Data Assimilation

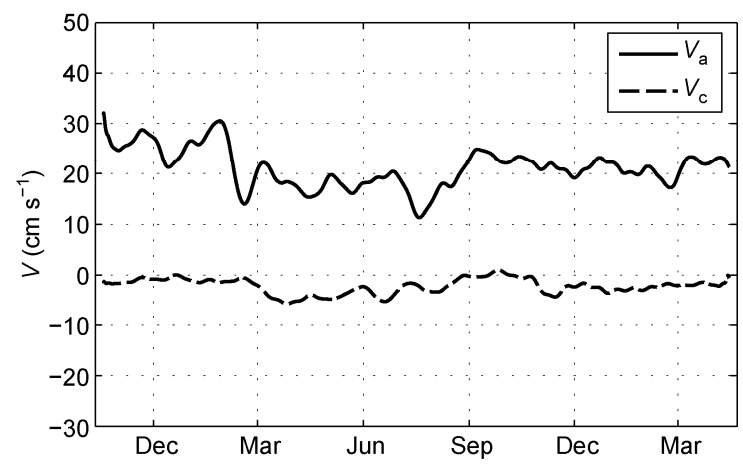

Figure 4 Background current extracted from mooring observation at the BC, from October 2009 to April 2011. Solid/dash line indicates along/ cross-channel velocity after counterclockwise coordinate rotation of $145^{\circ}$. 


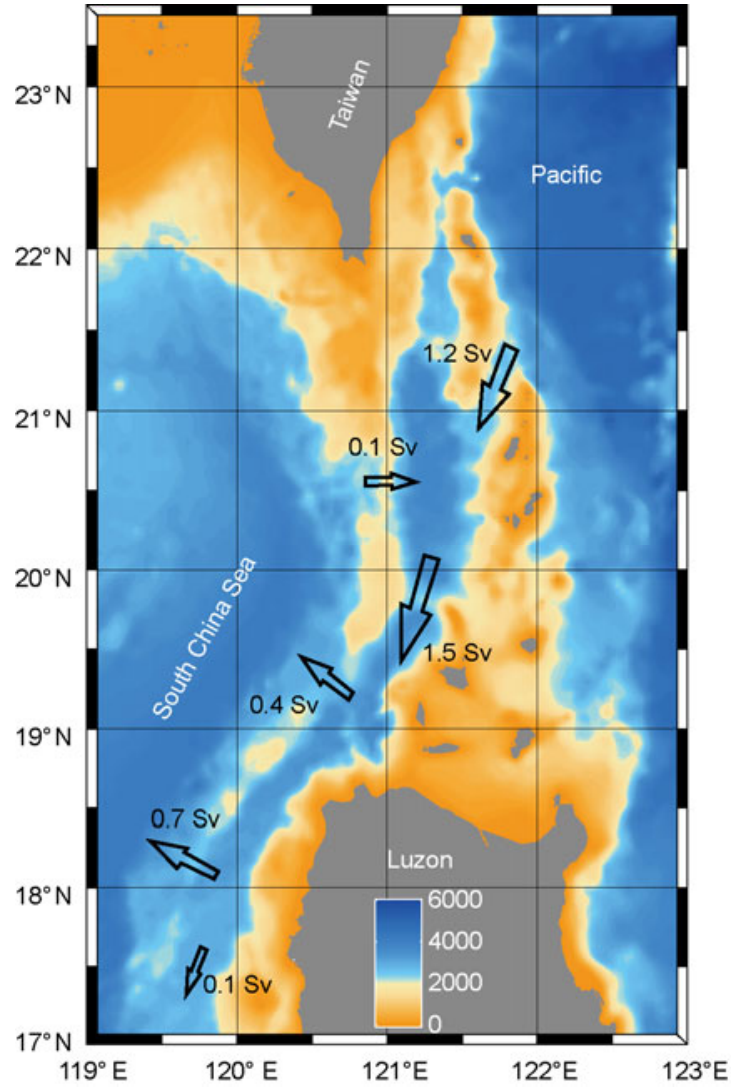

Figure 5 Vertically averaged velocity of deep flow below $36.83 \sigma 2$, and transports across channels at repeat-occupation stations.

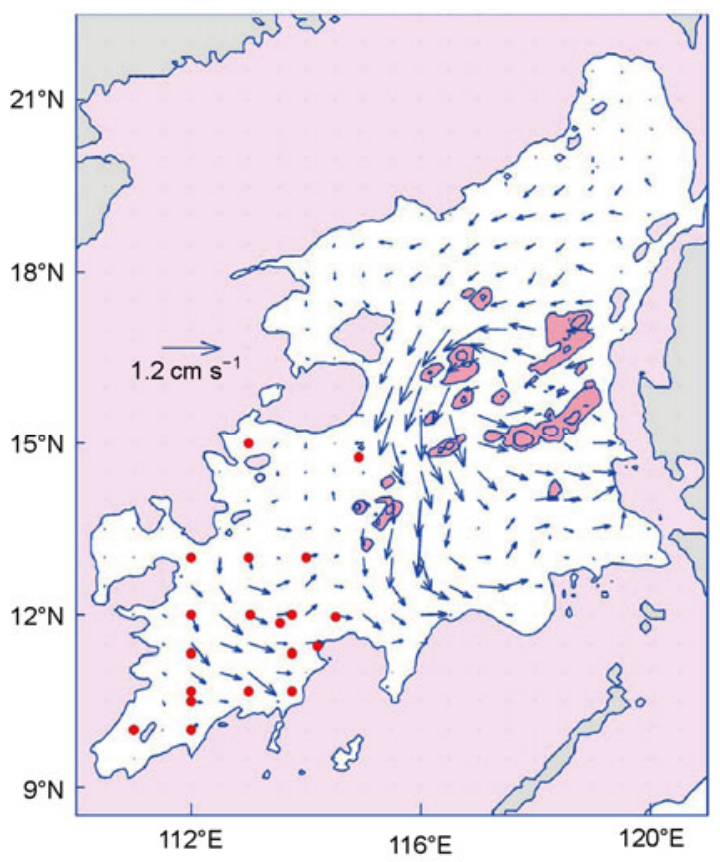

Figure 6 Vertically averaged geostrophic current $\left(\mathrm{cm} \mathrm{s}^{-1}\right)$ from $2400 \mathrm{~m}$ to the bottom. Light pink shading indicates water depths shallower than $2400 \mathrm{~m}$. Dark pink shading indicates sea mountains shallower than $3600 \mathrm{~m}$. Red solid dots denote stations where oxygen exceeds $2.15 \mathrm{~mL} \mathrm{~L}^{-1}$ at $3000 \mathrm{~m}$ layer [34].
(SODA), Wang et al. [35] calculated the meridional overturning circulation in the SCS (Figure 7). This figure reveals that the deep SCS water flowed southward with decreasing depth and turned back north in the surface layer, during which an upper-layer meridional overturning is evidenced. These results modified the deduction based on idealized bottom topography, described the general transport paths of bottom, intermediate and upper layers, and provided an idealized reference for further study on the dynamics of winddriven and thermohaline circulations of the SCS.

\section{Prospects of research on the deep SCS circulation}

Significant progress has been achieved with research on the deep SCS circulation. Nevertheless, several problems have been exposed, especially shortcomings in abyssal observation and techniques. These call for earnest consideration and profound exploration to determine effective resolutions.

\subsection{Achieving synchronous observation of macroscopic motions and microscopic mechanisms of deep SCS circulation}

Large-scale oceanic motions result from interactions among multi-scale dynamic processes. The study of these involves cascade theory, the key problem of turbulence theory, and the parameterization method, an exigent problem in need of resolution within ocean modeling. Interactions between large-/meso-scale barotropic motions in the SCS and Luzon Strait topography generates meso-/small-scale internal waves, which suggests the transition of energy from large-/ meso-scale motions to meso-/small-scale motions. Nonlinear interactions among internal waves and interactions between internal waves and bottom topography trigger the instability of interval waves, which further induces turbulence mixing. These processes are called direct cascades. In contrast, an inverse cascade suggests that turbulence processes

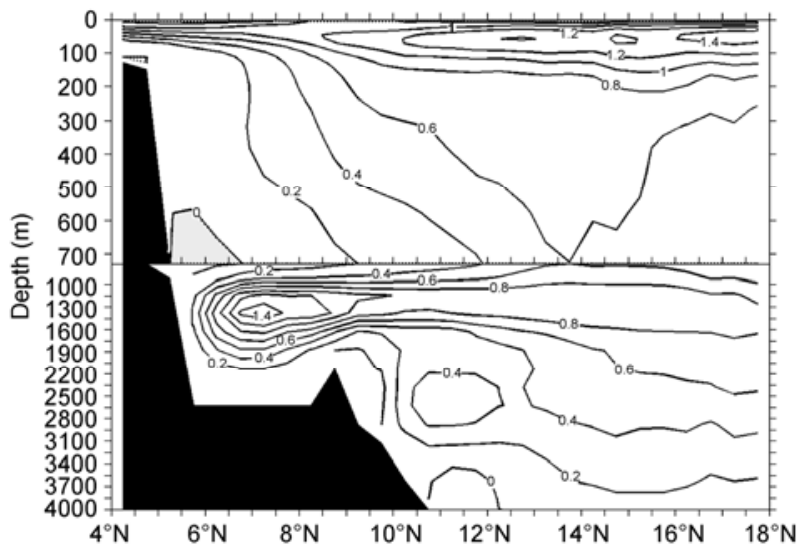

Figure 7 Climatological annual mean meridional-vertical stream function (Sv), calculated by SODA. 
dominate the density distribution and increase the potential energy of the entire system, which further modulates largescale oceanic circulation. With the advance of research on large-scale oceanic circulation, there is more attention directed toward multi-scale dynamic processes involving mesoscale eddies, internal waves, and others. This significantly shifts the focus of oceanic observation techniques, from large-scale to multi-scale processes. American scientists recently conducted synchronous observation of multi-scale dynamic processes in the upper ocean [36,37], furthering research on mechanisms of internal wave evolution and turbulence mixing processes. In short, deep dynamic processes in the SCS result from interactions and coexistence of multi-scale motions. Therefore, with a focus on issues like regulatory mechanism, variations and climatic effects of abyssal circulation, achieving synchronous observation of macroscopic motions and microscopic mechanisms of the deep SCS circulation is one of the prospects of abyssal observation.

\subsection{Promotion of effective long-term continuous observation of the deep SCS circulation}

The deep water exchange of the $\mathrm{BC}$ and abyssal mixing processes are major impacts on the deep SCS circulation. The circulation upstream of the deep BC (possibly a branch of the deep circulation of the Philippine Basin), the BC internal tide energy flux, and their variations, may directly influence the space-time structure and variability of the deep SCS circulation. Current studies show that the deepwater exchange in the $\mathrm{BC}$ varies significantly, from 0.2 to 1.2 Sv, and temperature in the deep northwest Pacific continues to increase [38]. These factors will modulate the deep SCS circulation and further affect the climate change of the SCS. Advances in research on abyssal science must be based on long-term continuous observation of deep-water exchange in the BC and Luzon Trough, with a focus on issues like variation of the deep SCS circulation. Also necessary are formulation of a long-term continuous observation system of the deep western boundary current in the area outside the $\mathrm{BC}$, and knowledge of the main pathways of SCS deep water and evolution of the deep SCS circulation.

\subsection{Integration and supplementary observation of essential data such as on SCS bottom topography}

Bottom topography consists of large-scale landforms like shelves and basins, mesoscale landforms like continental slopes, canyons, trenches, ridges, plus complex small-scale landforms. These multi-scale landforms shape pathways of the deep SCS circulation, trigger or scatter mesoscale and small-scale internal waves, and regulate small-scale turbulence mixing processes. The latter further modulate the structure of the deep SCS circulation. Complex landforms like continental shelves, slopes, BC, Luzon Trough, Manila
Trench, chains of volcanoes and canyons, generate and regulate various multi-scale oceanic processes. Nevertheless, given the absence of high-resolution topographic data for the SCS, only the ETOPO datasets can be used to study the deep SCS circulation. This constrains research on its dynamic processes. Given this present limitation, it is significant for the study of the deep SCS to make supplementary observations of the blank zone and build an integrated high-resolution topography dataset for the SCS.

\section{Conclusion}

Deep-sea circulation is important for world climate. It has been a substantial research topic in ocean science, leading to various breakthroughs and discoveries. With its various oceanic phenomena and processes, the SCS provides a natural platform for research on abyssal science. Hence, multidisciplinary study of abyssal science and synchronous development of abyssal observation technology and research, with emphasis on abyssal observation of the SCS, will advance research on the deep and open seas.

We thank Professor Wang Dongxiao from the South China Sea Institute of Oceanography, Chinese Academy of Sciences for providing the latest study results on meridional overturning circulation in the SCS. We also thank Professor Wang Guihua from the Second Institute of Oceanography, SOA for providing the latest results on deep SCS circulation, and Professor Tswen Yung Tang and PhD student Ya-ting Chang for the latest findings on the deep circulation in the Luzon Strait. We also thank the office and guidance group of "The South China Sea Deep" - Professor Liu Zhifei from Tongji University, Doctor Xie Lingling from Guangdong Ocean University, Professor Zhao Wei, Doctor Yang Qingxuan and M.S. student Zhou Chun from Ocean University of China - for their support and suggestions on the manuscript. We acknowledge technical support from the captain and crew of $R / V$ Dongfanghong No.2. This work was supported by the National Natural Science Foundation of China (40890153), the National High-tech R\&D Program of China (2008AA09A402), and the National Key Scientific Research Project "the South China Sea Deep" (91028008). Two anonymous reviewers provided helpful suggestions that improved the manuscript.

1 Qu T D, Du Y, Meyers G, et al. Connecting the tropical Pacific with Indian Ocean through South China Sea. Geophys Res Lett, 2005, 32: L24609

2 Wang P X, Li Q Y, eds. The South China Sea: Paleoceanography and Sedimentology. Heidelberg: Springer, 2009. 515

3 Shao L, Li X J, Geng J H, et al. Deep water bottom current deposition in the northern South China Sea. Sci China Ser D-Earth Sci, 2007, 50: 1060-1066

4 Lüdmann T, Wong H K, Berglar K. Upward flow of North Pacific Deep Water in the northern South China Sea as deduced from the occurrence of drift sediments. Geophys Res Lett, 2005, 32: L05614

5 Alford M H, Lien R-C, Simmons H, et al. Speed and evolution of nonlinear internal waves transiting the South China Sea. J Phys Oceanogr, 2010, 40: 1338-1355

6 Tian J W, Yang Q X, Liang X F, et al. Observation of Luzon Strait transport. Geophys Res Lett, 2006, 33: L19607

7 Tian J W, Yang Q X, Zhao W. Enhanced diapycnal mixing in the South China Sea. J Phys Oceanogr, 2009, 39: 3191-3203 
8 Yang Q X, Tian J W, Zhao W. Observation of Luzon Strait transport in summer 2007. Deep-Sea Res, 2010, 57: 670-676

9 Qu T D, Girton J B, Whitehead J A. Deepwater overflow through Luzon Strait. J Geophys Res, 2006, 111: 10.1029/2005JC003139

10 Lueck R G, Mudge T D. Topographically-induced mixing around a shallow seamount. Science, 1997, 276: 1831-1833

11 Thurnherr A M, Laurent L C, Speer K G, et al. Mixing associated with sills in canyons on the mid-ocean ridge flank. J Phys Oceanogr, 2005, 35: 1370-1381

12 Johnson G C, Toole J M. Flow of deep and bottom waters in the Pacific at $10^{\circ}$ N. Deep-Sea Res, 1993, 40: 371-394

13 Johnson G C, Rudnick D L, Taft B A. Bottom water variability in the Samoa Passage. J Mar Res, 1994, 52: 177-196

14 Rudnick D L. Direct velocity measurements in the Samoan Passage. J Geophys Res, 1997, 102: 3293-3302

15 Freeland $\mathrm{H}$. Observations of the flow of abyssal water through the Samoa Passage. J Phys Oceanogr, 2001, 31: 2273-2279

16 Kawabe M, Yanagimoto D, Kitagawa S, et al. Variations of the deep western boundary current in Wake Island Passage. Deep-Sea Res I, 2005, 52: 1121-1137

17 Hallock Z R, Teague W J. Evidence for a North Pacific deep western boundary current. J Geophys Res, 1996, 101: 6617-6624

18 Owens W B, Warren B A. Deep circulation in the northwest corner of the Pacific Ocean. Deep-Sea Res I, 2001, 48: 959-993

19 Warren B A, Owens W B. Deep currents in the central subarctic Pacific Ocean. J Phys Oceanogr, 1988, 18: 529-551

20 Wijffels S E, Toole J M, Bryden H L, et al. The water masses and circulation at $10^{\circ} \mathrm{N}$ in the Pacific. Deep-Sea Res, 1996, 43: 501-544

21 Nitani H. Oceanographic conditions in the sea east of the Philippines and Luzon Strait in the summer of 1965 and 1966. In: Marr J, ed. The Kuroshio-A Symposium on the Japan Current. Honolulu: East West Center Press, 1970. 213-232

22 Nitani H. Beginning of the Kuroshio, in Kuroshio. In: Stommel H, Yoshida K, eds. Physical Aspects of the Japan Current. Seattle: University of Wash Press, 1972. 129-163

23 Broecker W S, Patzert W C, Toggweiler J R, et al. Hydrography, chemistry, and radioisotopes in the southeast Asian basins. J Geophys Res, 1986, 91: 14345-14354
24 Wang J. Observation of abyssal flows in the Northern South China Sea. Acta Oceanogr Taiwan, 1986, 16: 36-45

25 Liu C-T, Liu R-J. The deep current in the Bashi Channel. Acta Oceanogr Taiwan, 1988, 20: 107-116

26 Shaw P T. The intrusion of water masses into the sea southwest of Taiwan. J Geophys Res, 1989, 94: 18213-18226

27 Gong G-C, Liu K K, Liu C-T, et al. The chemical hydrography of the South China Sea west of Luzon and a comparison with the west Philippine Sea. Acta Oceanogr Taiwan, 1992, 3: 587-602

28 Chen C-T A, Wang S-L. Influence of the intermediate water in the western Okinawa Trough by the outflow from the South China Sea. J Geophys Res, 1998, 103: 12683-12688

29 Qu T D, Mitsudera H, Yamagata T. Intrusion of the North Pacific waters into the South China Sea. J Geophys Res, 2000, 105: 6415-6424

30 Qu T D. Evidence of water exchange between the South China Sea and the Pacific through the Luzon Strait. Acta Oceanol Sin, 2002, 21: $175-185$

31 Qu T D, Lindstrom E J. Northward intrusion of Antarctic Intermediate Water in the western North Pacific. J Phys Oceanogr, 2004, 34: 2104-2118

32 Xie L L, Tian J W, Hu D X, et al. A quasi-synoptic interpretation of water mass distribution and circulation in the western North Pacific: II circulation. Chin J Oceanol Limnol, 2009, 27: 955-965

33 Chang Y T, Hsu W L, Tai J H, et al. Cold deep water in the South China Sea. J Oceanogr, 2010, 66: 183-190

34 Wang G H, Xie S P, Qu T D, et al. Deep South China Sea circulation. Geophys Res Lett, 2011, doi: 10.1029/2010GL046626

35 Wang D X, Liu X B, Wang W Z, et al. Simulation of meridional overturning in the upper layer of the South China Sea with an idealized bottom topography. Chin Sci Bull, 2004, 49: 740-747

36 Moum J N, Lien R-C, Perlin A, et al. Sea surface cooling at the equator by subsurface mixing in tropical instability waves. Nat Geosci, 2009, 2: 761-765

37 Zhang Y W, Moum J N. Inertial-convective subrange estimates of thermal variance dissipation rate from moored temperature measurements. J Atmos Oceanic Technol, 2010, 27: 1950-1959

38 Masuda S, Awaji T, Sugiura N, et al. Simulated rapid warming of abyssal North Pacific waters. Science, 2010, 329: 319-322

Open Access This article is distributed under the terms of the Creative Commons Attribution License which permits any use, distribution, and reproduction in any medium, provided the original author(s) and source are credited. 